\title{
Efficient organic/polycrystalline silicon hybrid solar
}

\section{cells}

Qiming Liu ${ }^{\mathrm{a}, 1}$, Tatsuya Ohki ${ }^{\mathrm{a}}$, Dequan Liu ${ }^{\mathrm{b}}$, Hiromitsu Sugawara ${ }^{\mathrm{a}}$, Ryo Ishikawa ${ }^{\mathrm{a}}$, Keiji Ueno ${ }^{\mathrm{a}}$, and Hajime Shirai ${ }^{\text {a,* }}$

a Graduate School of Science and Engineering, Saitama University, Saitama, 338-8570 Japan.

b International Center for Materials Nanoarchitectonics (MANA), National Institute for Materials

Science, Tsukuba, 305-0047 Japan

\begin{abstract}
We firstly investigated efficient poly(3,4-ethylenedioxythiophene): poly(styrenesulfonic acid) (PEDOT:PSS)/n-type polycrystalline silicon (p-Si) heterojunction solar cells fabricated by chemical mist deposition (CMD) using a high-pressure $\mathrm{H}_{2} \mathrm{O}$-vapor-treated p-Si prior to organic film deposition. High-pressure $\mathrm{H}_{2} \mathrm{O}$ vapor treatment of the p-Si efficiently suppressed grain boundary defects and improved carrier transport at the PEDOT:PSS/p-Si interface. Furthermore, compared to spin coated devices, the CMD devices demonstrated a more uniform photovoltaic
\end{abstract}

${ }^{1}$ Corresponding author at Graduate School of Science and Engineering, Saitama University. Saitama, 338-8570 Japan.

Phone: +81-048-858-3676

Email address: Liuqm670@gmail.com (Q. Liu), Shirai@fms.saitama-u.ac.jp (H. Shirai). 
performance. The power conversion efficiency of the PEDOT:PSS/p-Si heterojunction solar cells was $9.7 \%$ with a short-circuit current density of $33.5 \mathrm{~mA} / \mathrm{cm}^{2}$, an open-circuit voltage of $0.54 \mathrm{~V}$, and a fill factor of 0.53 . These findings suggest that CMD with a negatively charged mist precursor provides uniform adhesion of PEDOT:PSS on p-Si, resulting in increased photovoltaic performance.

\section{Keywords}

Polycrystalline silicon; Hybrid solar cells, Surface passivations, Conjugated polymers, Bulk heterojunctions

\section{Introduction}

Conjugated polymer-silicon heterojunction solar cells composed of an n-type crystalline silicon (c-Si) and organic poly(ethylene dioxythiophene):poly(styrene sulfonate acid)(PEDOT:PSS) layers provide the unique possibility of combining the high energy conversion efficiency of c-Si solar cells with the potentially low fabrication cost of organic solar cells. Promising efficiencies of $\sim 12 \%$ have already been reported [1-10], and the highest efficiencies were realized by either passivating the organic-silicon interface using an ultrathin interface-passivating tunneling silicon oxide $\left(\mathrm{SiO}_{\mathrm{x}}\right)$ layer containing carbon nanotubes, molybdenum tri-oxide $\left(\mathrm{MoO}_{3}\right)$, and ferroelectric polymer poly(vinylidene fluoride-tetrafluoroethylene) $\mathrm{P}(\mathrm{VDF}-\mathrm{TeFE})$, graphene, graphene oxide, and metal nanowires at the c-Si/PEDOT:PSS interface [11-15]. The passivation layers can be fabricated by a simple solution process such as spin coating (SC), and its work function can be easily tuned as desired to optimize the device performance. These findings suggest that the 
organic films could be used as a surface passivation layer for c-Si, similar to $\mathrm{SiO}_{2}$ and $\mathrm{SiN}_{\mathrm{x}}$, although the optical and carrier transport properties depend on the solvent and preparation method [16].

To date, most research efforts have predominantly focused on the effects of the c-Si surface morphology, passivation, and the optical and carrier transport properties of PEDOT:PSS [16,17]. To further improve device performance, the usage of textured c-Si can increase the effective optical path of incident light inside absorbing materials by light trapping or scattering. However, for spin coating (SC), the uniformity of the organic layer on textured c-Si is insufficient, and causes performance variation $[7,18]$. Therefore, we attempted organic deposition by chemical mist deposition (CMD) using a negatively charged mist precursor. The optical properties and hole mobility of PEDOT:PSS can be controlled during film growth by CMD using a negative DC bias to charge the mist precursor [19]. Better uniformity of PEDOT:PSS on textured c-Si(100) and an average $\eta$ of $12.7 \%$ were obtained with a short-circuit density $J_{\mathrm{sc}}$ of $35 \mathrm{~mA} / \mathrm{cm}^{2}$, an opencircuit voltage $\mathrm{V}_{\text {oc }}$ of $0.54 \mathrm{~V}$, and a fill factor $F F$ of 0.68 due to enhanced light trapping. Thus, CMD is also expected to provide a uniform organic coating on micro-roughened substrates such as a p-Si board using the cast method to provide low-cost photovoltaic devices.

In the present paper, we demonstrate for the first time the efficient photovoltaic performance of conductive PEDOT:PSS/n-type p-Si heterojunction solar cells. We observed a relatively high $\eta$ of $9.7 \%$ after combining defect passivation of the p-Si with a uniform organic layer deposited by CMD using a charged mist precursor.

\section{Experimental section}




\section{High pressure water vapor treatment}

Polycrystalline silicon substrates with a size of $2 * 2 \mathrm{~cm}^{2}$ were ultrasonically cleaned in methanol, acetone and deionized(DI) water for $10 \mathrm{~min}$ each. Samples were subsequently immersed in $5 \%$ HF solution to remove native oxide layer, followed by placing in a $100 \mathrm{~mL}$ size Teflon-lined stainless autoclave with $10 \mathrm{~mL}$ DI water. Inside-chamber is Teflon made container for setting the samples, outside is stainless made frame for high pressure prevention. The closed reactor was then contained in the thermostat at $100^{\circ} \mathrm{C} / 200^{\circ} \mathrm{C}$ for hours and stay overnight for cooling down. Saturation vapor pressure of water under $200^{\circ} \mathrm{C}$ is $16 \mathrm{P}_{0}$.

\section{Solar cells Fabrication}

The devices were fabricated use polycrystalline silicon wafer with a thickness around $200 \mu \mathrm{m}$, resistivity of 1-3 $\Omega \cdot \mathrm{cm}$, with and without high pressure treatment. The native oxide was removed by dipping the samples in 5\% HF solution for 3 min. Then, the wafers were cleaned by RCA cleaning and left in air for 6h. Highly conductive PEDOT:PSS (Clevios ${ }^{\mathrm{TM}} \mathrm{PH} 1000$ ) solution mixed with 5wt\% dimethyl sulfoxide (DMSO) and 0.01wt\% Zonyl fluorosurfactant (Sigma Aldrich) was spin-coated at $3000 \mathrm{rpm}$ for $1 \mathrm{~min}$, followed by annealing at $140^{\circ} \mathrm{C}$ for $20 \mathrm{~min}$. In the case of CMD deposition, process is described in more detail in refs.19 and 24. The apparatus consists of an ultrasonic atomization reactor, a glass tube with a $20 \mathrm{~mm}$ outer diameter, a mesh electrode to supply a DC bias for charging the mist deposition precursor, and substrate stage. Commercialized PEDOT:PSS (CLEVIOS PH1000) was used as a starting material. An aqueous solution of 5wt\% DMSO added conductive PEDOT:PSS diluted in DI water and EG(10 wt\%) cosolvents was placed in an ultrasonic vibrator with a working frequency of $3 \mathrm{MHz}$ for mist 
generation followed by thermal annealing at $140^{\circ} \mathrm{C}$ for 20 min to remove any residual solvent. After that, a top Ag grid electrode (finger electrode: $1 \mathrm{~mm}$ in width, bus bar: $2 \mathrm{~mm}$ in width and $18 \mathrm{~mm}$ in length) was formed from a silver paste using a screen printer (Newlong Seimitsu Kogyo Co., Ltd. DP-320). Finally, an InGa alloy was used to form ohmic contact as a rear electrode.

\section{Samples characteristic}

The samples were characterized by Scanning Electron Microscopy (SEM), Fourier-transform infrared spectroscopy (FTIR), and imaging Raman spectroscopy (Renishaw: inVia Raman microscope: $532 \mathrm{~nm}$ ). The carrier mobility $\mu$ and accepter concentration $N_{\mathrm{a}}$ of n-type p-Si before and after high-pressure $\mathrm{H}_{2} \mathrm{O}$ vapor treatment was determined for poly-Si with an $1 \times 1 \mathrm{~cm}^{2}$ area from Hall measurements in a van der Pauw configuration. The capacitance-voltage $(C-\mathrm{V})$ and $C$ $f\left(f\right.$ : measurement frequency) characteristics were also measured with a $1 \mathrm{~mm}^{2} \mathrm{Ag}$ top electrode to understand the carrier transport properties at the PEDOT:PSS/p-Si interface. The current density-voltage $(J-V)$ characteristics of solar cell device structure in the dark and under AM1.5G, $100 \mathrm{~mW} / \mathrm{cm}^{2}$ simulated solar light illumination (Bunkoukeiki CEP-25BX) were measured. A 2-

dimensional map of the photovoltaic parameters, $J_{\mathrm{sc}}, \mathrm{V}_{\mathrm{oc}}, F F$, $\eta$, and the external quantum efficiency (EQE) of the devices $\left(2 \times 2 \mathrm{~cm}^{2}\right)$ were also measured using a line-illumination scan combined with computer tomography calculations (MAP: MP50, Lasertec Co., Ltd.).

\section{Results and discussions}


Figure 1(a) shows the molecular structure of PEDOT:PSS and a schematic of a PEDOT:PSS/p-Si heterojunction solar cells. An n-type p-Si wafer with a resistivity of $1-3 \Omega \cdot \mathrm{cm}$ and a thickness of $\sim 200 \mu \mathrm{m}$ was used in this study. The p-Si wafer was pre-treated with a high-pressure $\mathrm{H}_{2} \mathrm{O}$ vapor at $1.6 \mathrm{GPa}$ and $200{ }^{\circ} \mathrm{C}$ for $2 \mathrm{~h}$ to terminate dangling bond defects at the grain boundaries [20, 21]. Following that, the wafer was dipped in $5 \%$ hydrofluoric (HF) acid to remove the surface oxidized layer. Then, the wafers were cleaned by RCA cleaning and left in air for $6 \mathrm{~h}[6,22,23]$.

(a)

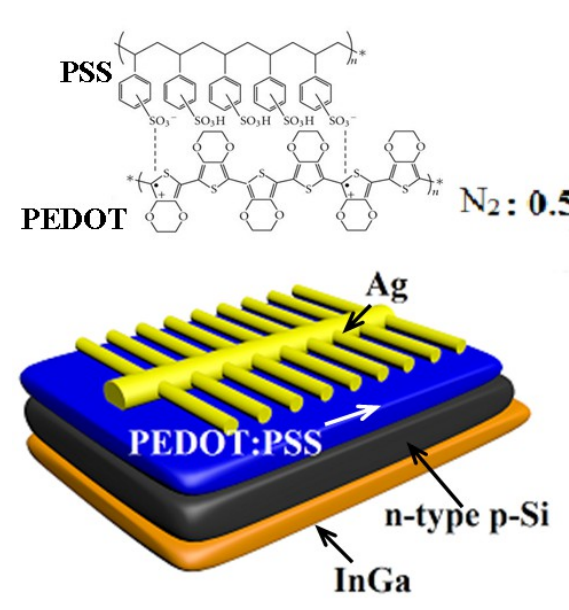

(b)

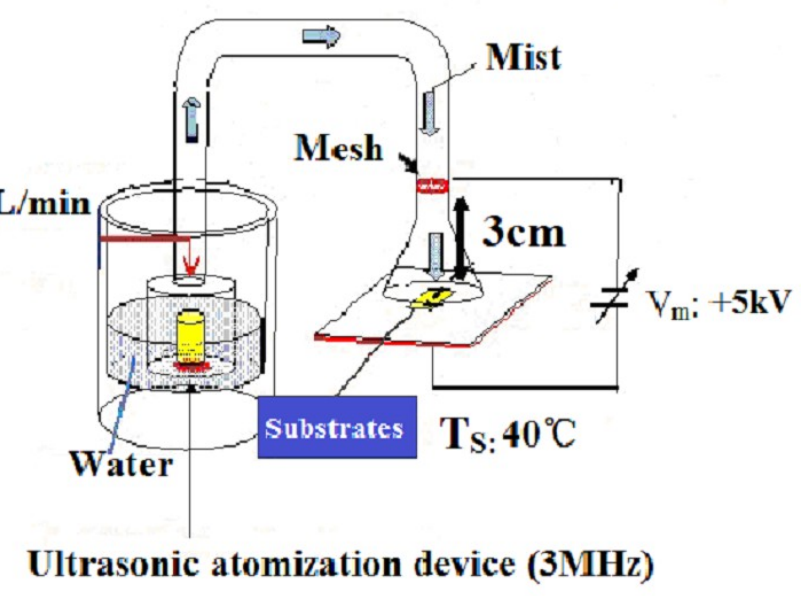

Figure. 1 (a) Schematic of a PEDOT:PSS/p-Si heterojunction photovoltaic device and the molecular structure of PEDOT:PSS. (b) Schematic of the CMD apparatus used in this study.

Figure 1(b) shows a schematic of the CMD apparatus. The PEDOT:PSS mist was transported through a glass tube using a $\mathrm{N}_{2}$ as a carrier gas at 0.5 SLM and then, passed through a mesh electrode $3 \mathrm{~cm}$ from the substrate stage. The film deposition was performed with a mesh DC bias of $+5 \mathrm{kV}$ and a substrate temperature $\mathrm{T}_{\mathrm{s}}$ of $40^{\circ} \mathrm{C}$. The film deposition rate was $\sim 10 \mathrm{~nm} / \mathrm{min}$ and 
the resulting film thickness was 100 120 nm. For comparison, an SC device was also fabricated using an identical aqueous solution of $5 \mathrm{wt} \%$ DMSO added PEDOT:PSS at $3000 \mathrm{rpm}$ for $60 \mathrm{~s}$ followed by drying at $140^{\circ} \mathrm{C}$ for $30 \mathrm{~min}$.

Figure 2(a) shows an FTIR spectrum of a p-Si wafer after a high-pressure $\mathrm{H}_{2} \mathrm{O}$ vapor treatment and a subsequent 5\% HF rinse for 30 s. The spectrum is shown referred to that of an un-treated poly-Si wafer. Si-O-Si and SiO related absorption peaks appeared in the $800-1250 \mathrm{~cm}^{-1}$ regions with $\mathrm{CH}\left(2990 \mathrm{~cm}^{-1}\right)$ and $\mathrm{SiOH}\left(3000 \sim 3500 \mathrm{~cm}^{-1}\right)$ peaks, suggesting that oxygen atoms were incorporated into the p-Si and that some of these oxygen atoms contributed to the termination of dangling bonds at grain boundaries. Figure 2(b) shows a $1 / C^{2}-\mathrm{V}$ plot at $1 \mathrm{MHz}$ and the $C-f(f$ : measurement frequency) characteristics of SC and CMD Ag(1 mm²)/PEDOT:PSS(100 nm thick)/p-Si diodes with and without a high-pressure $\mathrm{H}_{2} \mathrm{O}$ vapor treatment. For reference, the results for an untreated p-Si device with SC PEDOT:PSS is also shown as a reference. $N_{\mathrm{d}}$ of the p-Si was determined from the slope of the $1 / C^{2}-\mathrm{V}$ plot relating to $1 / N_{\mathrm{a}}+1 / N_{\mathrm{d}}\left(N_{\mathrm{a}}\right.$, charge carrier density of PEDOT:PSS). Here, the $N_{\mathrm{a}}$ value of $1.1 \times 10^{21} \mathrm{~cm}^{-3}$ obtained from our previous $C$-V and spectroscopy ellipsometry (SE) studies was used for PEDOT:PSS [5, 24]. The $1 / C^{2}-\mathrm{V}$ plot for the untreated p-Si diode showed a non-linear relationship, suggesting that space charge was accumulated at grain boundaries and/or the PEDOT:PSS/p-Si interface. Additionally, the $N_{\mathrm{d}}$ for non-treated p-Si was $\sim 4 \times 10^{17} \mathrm{~cm}^{-3}$, nearly two orders of magnitude higher than the doping concentration $\left(0.5-1 \times 10^{16} \mathrm{~cm}^{-3}\right)$. On the other hand, $1 / C^{2}-\mathrm{V}$ plots for SC and CMD diodes on treated p-Si showed linear relationships, suggesting that the depletion region widened to p-Si. The calculated $N_{\mathrm{d}}$ value was suppressed to $2 \times 10^{16} \mathrm{~cm}^{-3}$, which was consistent with the doping density of the p-Si. Hall measurements of the p-Si also revealed that $N_{\mathrm{d}}$ decreased from $7.8 \times 10^{16}$ 
to $1.9 \times 10^{15} \mathrm{~cm}^{-3}$ with increasing Hall mobility $\mu_{\mathrm{H}}$ from $\sim 2$ to $\sim 15 \mathrm{~cm}^{2} / \mathrm{Vs}$ after the treatment, which was a similar tendency to that for the $1 / C^{2}-\mathrm{V}$ measurements. On the other hand, the slope

(a)

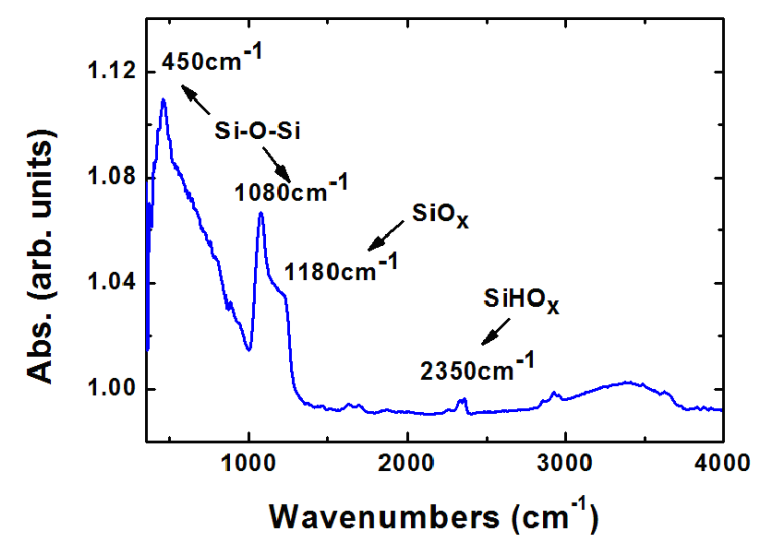

(b)

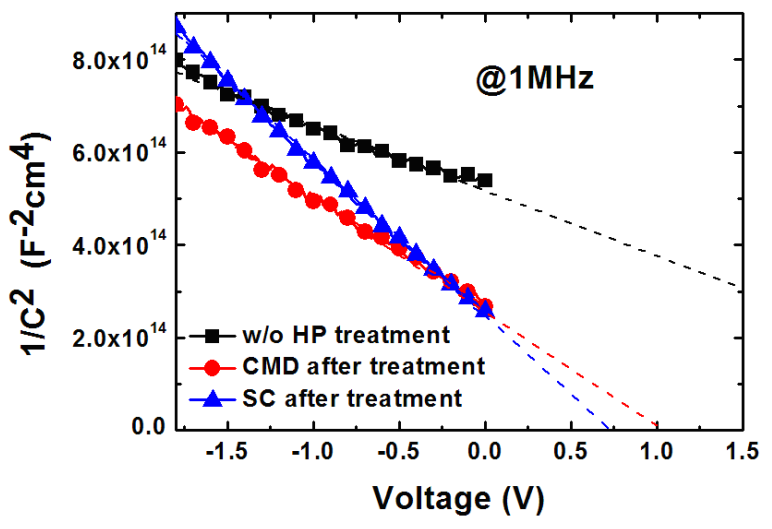

(c)

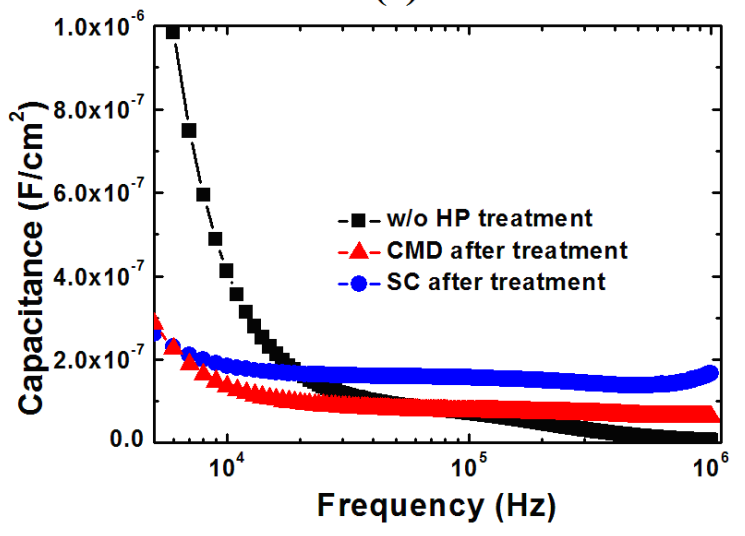


Figure. 2 (a) FTIR spectrum of p-Si treated by high-pressure $\mathrm{H}_{2} \mathrm{O}$ vapor at $200^{\circ} \mathrm{C}$ for $2 \mathrm{~h}$. (b) $1 / C^{2}-\mathrm{V}$ and (c) $C$-f plots of SC and CMD PEDOT:PSS/p-Si diodes after high-pressure $\mathrm{H}_{2} \mathrm{O}$ vapor treatment. The results for an SC PEDOT:PSS diode on untreated p-Si are also shown for comparison.

of the $1 / C^{2}-\mathrm{V}$ plot was lower for the CMD diode on high-pressure $\mathrm{H}_{2} \mathrm{O}$ vapor treated p-Si than for SC, implying an enhanced $N_{\mathrm{d}}$ and/or carrier mobility in the PEDOT:PSS. The built-inpotential $\mathrm{V}_{\mathrm{b}}$ was $\sim 0.7 \mathrm{~V}$ for the $\mathrm{SC}$ diode, whereas $\mathrm{V}_{\mathrm{b}}$ was $\sim 1 \mathrm{~V}$ for the CMD diode. Furthermore, the junction capacitance was almost independent of $f$ and was lower, for both SC and CMD devices on treated p-Si substrates than on untreated p-Si wafers: in the lower measurement-frequency region, implying a suppressed interface defect density in treated p-Si substrates [25].

Figure 3(a) shows photocurrent density $J_{\mathrm{p}}-\mathrm{V}$ curves for SC PEDOT:PSS/p-Si heterojunction solar cells with high-pressure $\mathrm{H}_{2} \mathrm{O}$ vapor treatment under different conditions. The results for untreated p-Si device are also shown for reference. $\eta$ increased markedly from $\sim 4 \%$ for a pristine organic/p-Si device to $\sim 7 \%$ for one treated at $200^{\circ} \mathrm{C}$ for $2 \mathrm{~h}$. Figure 3(b) shows a 2-dimensional map of $J_{\text {sc }}$ and EQE at $950 \mathrm{~nm}$ for PEDOT:PSS/p-Si heterojunction solar cells $\left(2 \times 2 \mathrm{~cm}^{2}\right)$ with and without the treatment. Fine structures attributed to defects in the p-Si such as twin boundaries, dislocation, and screw transition were clearly observed in the $J_{\text {sc }}$ and EQE maps of the untreated device, whereas these fine structures almost disappeared from the treated device. These findings suggest that high-pressure $\mathrm{H}_{2} \mathrm{O}$ vapor treatment can suppress dangling bond defects in entire p-Si regions. 
(a)

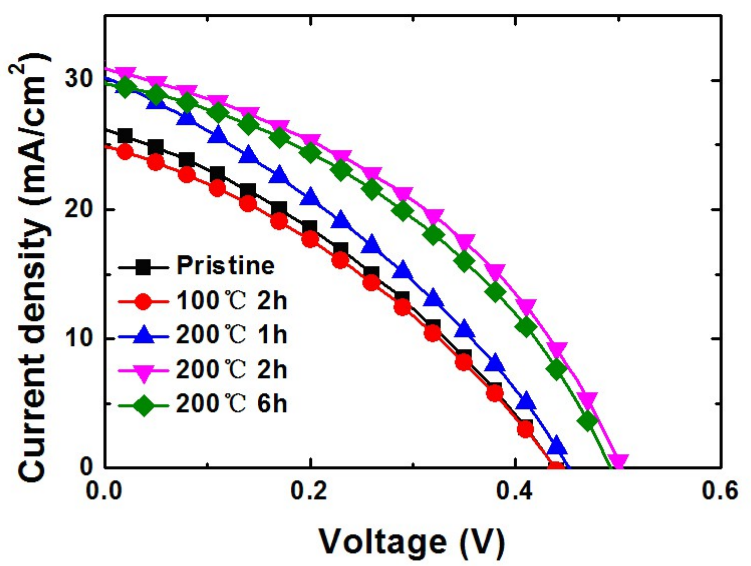

(b)

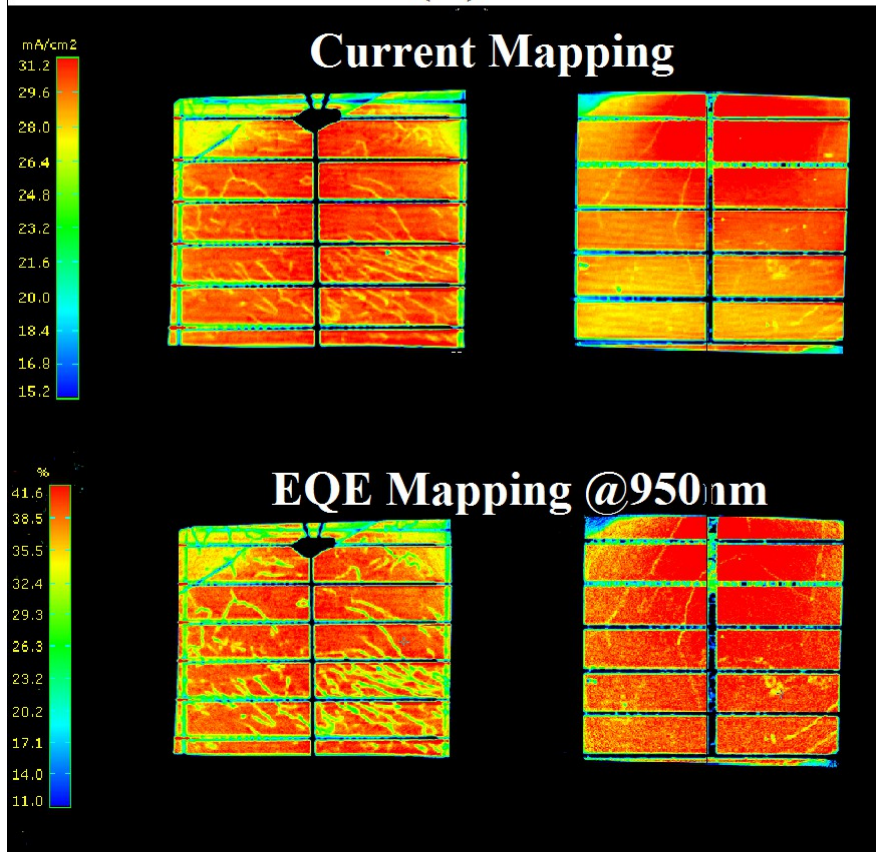

Figure. 3 (a) $J$-V curves of corresponding PEDOT:PSS/p-Si solar cells shown in Fig. 2. (b) 2D map of $J_{\mathrm{sc}}$ and EQE at $950 \mathrm{~nm}$ of a $2 \times 2 \mathrm{~cm}^{2}$ area before and after high-pressure $\mathrm{H}_{2} \mathrm{O}$ vapor treatment at $200^{\circ} \mathrm{C}$ for $2 \mathrm{~h}$. 
Figure 4(a) shows optical microscopy images of SC and CMD 100-nm-thick PEDOT:PSS on pSi along with a 2D map of the imaging Raman peak intensity at $1350-1500 \mathrm{~cm}^{-1}$ corresponding to the $\mathrm{C}=\mathrm{C}$ bond of PEDOT. The typical Raman spectra of corresponding sample measured at two different positions are also shown [26]. Spotted distribution of PEDOT:PSS was observed for the SC film, whereas the imaging Raman intensity was more uniform for the CMD film. SEM images of SC and CMD PEDOT:PSS on p-Si are also shown in Fig. 4(b). Several separated regions were observed in the SC film, whereas a uniform coating was observed for the CMD film, although this depended on the choice of solvent and the mesh bias.

In Fig. 4(c), the $J$-V characteristics measured at four different positions $\left(5 \times 5 \mathrm{~mm}^{2}\right)$ are shown for SC and CMD PEDOT:PSS/p-Si heterojunction devices under illumination by AM1.5G 100 $\mathrm{mW} / \mathrm{cm}^{2}$ simulated solar light. The average photovoltaic parameters, i.e., $\mathrm{V}_{\mathrm{oc}}, J_{\mathrm{sc}}, F F$, and $\eta$ are summarized for the devices in Table I. The performance was uneven and the devices for the SC PEDOT:PSS buffer layer exhibited an average $\eta$ of 6-8\%, although a maximum $\eta$ was achieved of a $\eta$ of $9.8 \%$ with a $J_{\text {sc }}$ of $30.5 \mathrm{~mA} / \mathrm{cm}^{2}$, a $\mathrm{V}_{\text {ос }}$ of $0.52 \mathrm{~V}$, and a $F F$ of 0.62 . On the other hand, uniform performance was provided relatively with an average $\eta$ value of $\sim 9 \%$. The best performance was obtained with a $\eta$ of $9.7 \%$, a $J_{\text {sc }}$ of $33.5 \mathrm{~mA} / \mathrm{cm}^{2}$, a $\mathrm{V}_{\text {oc }}$ of $0.54 \mathrm{~V}$, and a $F F$ of 0.53. Obviously, larger variation in data of $J_{\mathrm{p}}-\mathrm{V}$ curve was observed for SC devices, whereas it was suppressed relatively for the CMD device. The improvement in the device performance can be attributed to the use of CMD with a charged mist precursor. In particular, $J_{\text {sc }}$ improved from 29 to $33 \mathrm{~mA} / \mathrm{cm}^{2}$ with a $\mathrm{V}_{\text {oc }}$ of $0.53-0.54 \mathrm{~V}$ by the CMD rather than the SC, although a FF value was still 0.5. These findings imply that the carrier transport at the PEDOT:PSS/p-Si interface is improved by the combination of a high-pressure $\mathrm{H}_{2} \mathrm{O}$ vapor treatment of p-Si prior to the film 
Table 1. Performance details $\left(\mathrm{V}_{\mathrm{oc}}, J_{\mathrm{sc}}, F F\right.$, and $\eta$ ) of CMD and SC PEDOT:PSS/p-Si heterojunction solar cells measured at four different positions, a, b, c, and d $\left(5 \times 5 \mathrm{~mm}^{2}\right)$.

\begin{tabular}{ccccc}
\hline Device & $\boldsymbol{J}_{\text {sc }}\left(\mathbf{m A} \mathbf{\mathbf { c m } ^ { 2 }}\right)$ & $\mathbf{V}_{\text {oc }}(\mathbf{V})$ & $\boldsymbol{F . F .}$ & $\eta(\mathbf{\%})$ \\
\hline CMD & 33.6 & 0.53 & 0.48 & 8.5 \\
CMD & 33.5 & 0.54 & 0.53 & 9.7 \\
CMD & 33.0 & 0.54 & 0.54 & 9.6 \\
CMD & 32.4 & 0.54 & 0.51 & 8.8 \\
\hline SC a & 27.2 & 0.48 & 0.46 & 5.9 \\
SC b & 28.4 & 0.45 & 0.46 & 5.9 \\
SC c & 29.5 & 0.49 & 0.58 & 8.4 \\
SC d & 30.5 & 0.52 & 0.62 & 9.8 \\
\hline
\end{tabular}




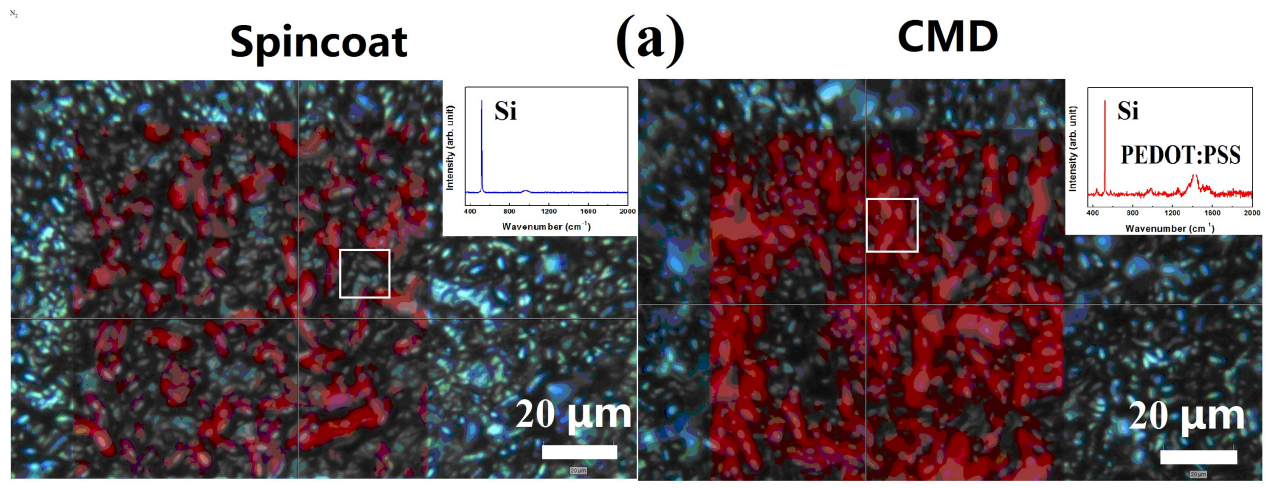

(b)
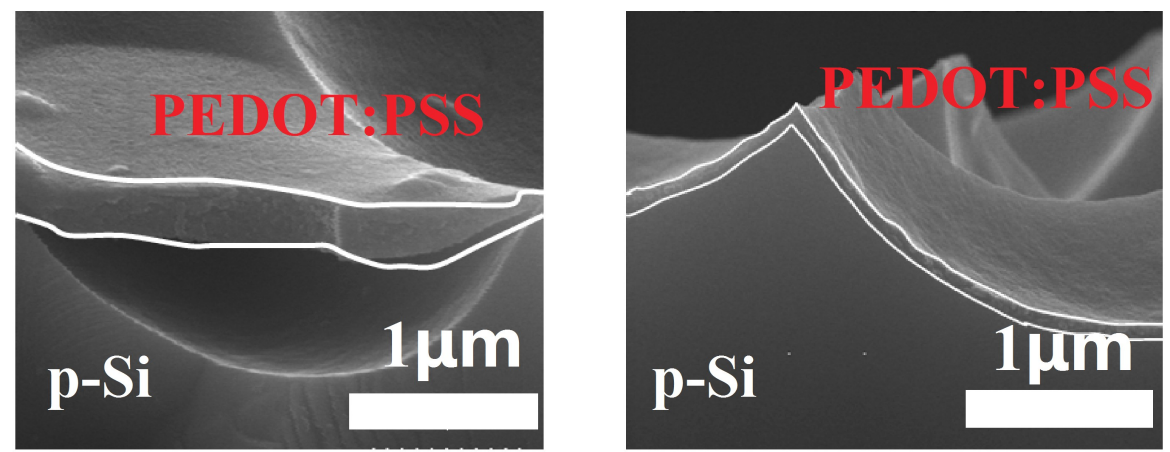

(c)
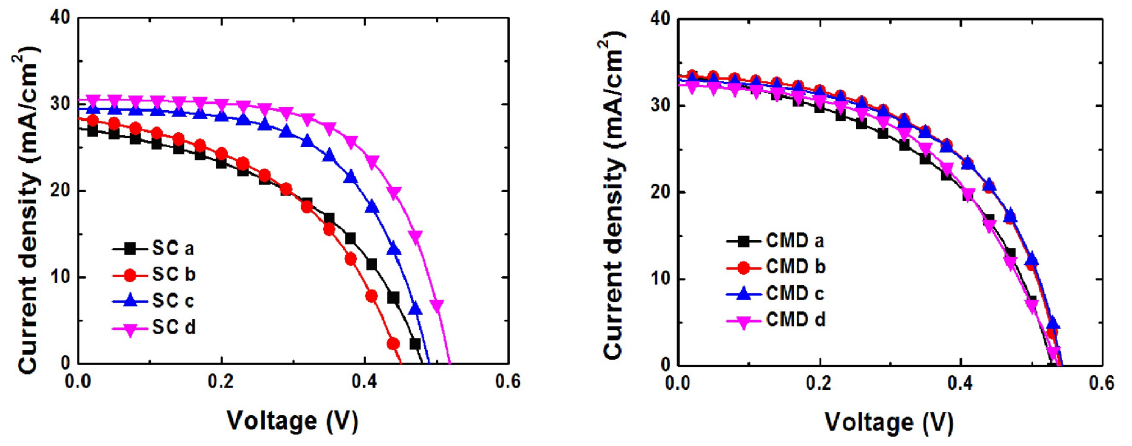

Figure. 4 (a) Microscope images of SC and CMD PEDOT:PSS on high-pressure $\mathrm{H}_{2} \mathrm{O}$ vapor treated p-Si with a 2D map of the imaging Raman intensity at $1400-1500 \mathrm{~cm}^{-1}$ corresponding to the $\mathrm{C}=\mathrm{C}$ bond of PEDOT at two different positions. Scanning area was $0.1 \times 0.1 \mathrm{~mm}^{2}$ (b) SEM image of SC and CMD PEDOT:PSS on p-Si. (c) $J$-V curves of 
corresponding PEDOT:PSS/p-Si heterojunction solar cells measured at four different positions under simulated AM1.5G solar light illumination. The active area was $5 \times 5 \mathrm{~mm}^{2}$.

deposition of organic and an use of CMD. Thus, the role of these procedures is considered as the suppression of grain boundary defect of p-Si and PEDOT:PSS/p-Si interface. As far as the SC is concerned, the variation of $J-\mathrm{V}$ characteristics is larger at each measurement position due to the inhomogeneous coating, whereas it was suppressed relatively for the CMD device with increased $J_{\mathrm{sc}}$ and $\mathrm{V}_{\mathrm{oc}}$ values. These findings are mainly due to the improved uniformity and adhesion of organic on $\mathrm{p}-\mathrm{Si}$, which lower defect at the organic/p-Si interface, resulting in the increased PV performance.

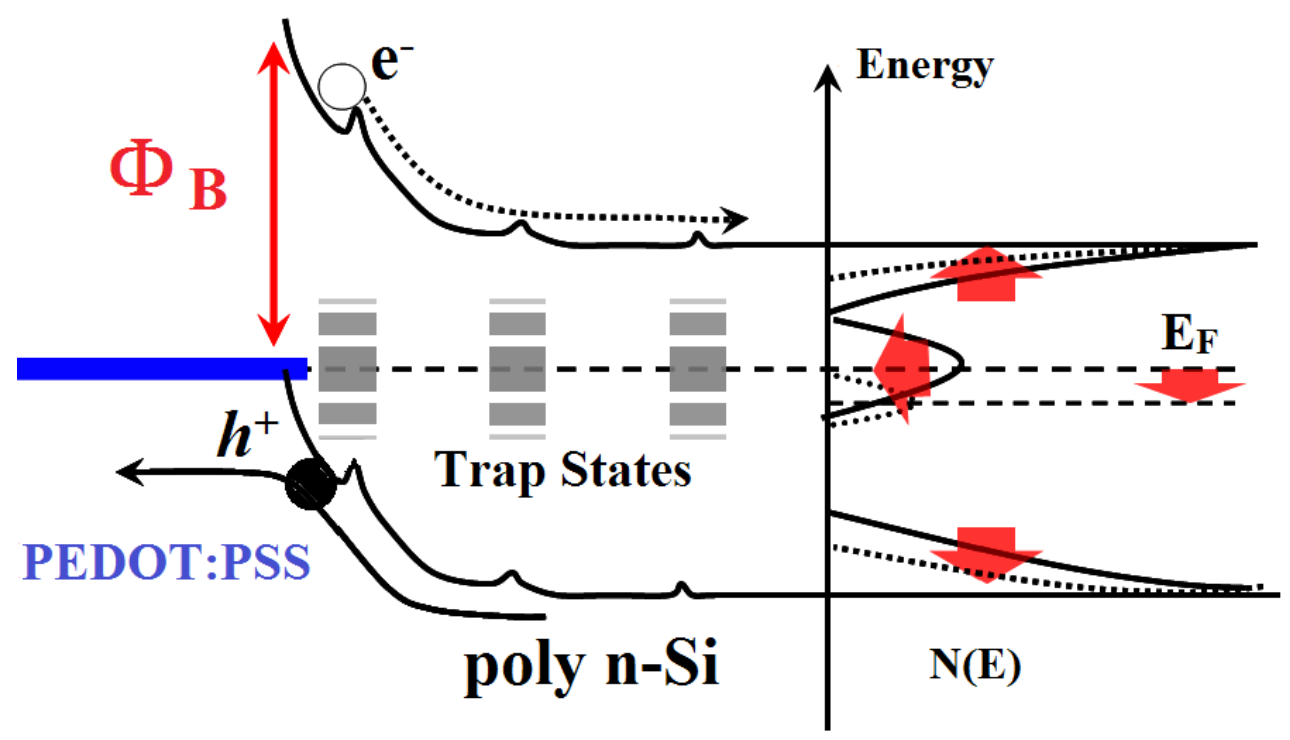

Figure. 5 Schematic of the band potential of PEDOT:PSS/p-Si interface and the density of states of p-Si before and after high-pressure $\mathrm{H}_{2} \mathrm{O}$ vapor treatment. 
Figure 5 shows a schematic of the band diagram of PEDOT:PSS/p-Si interface region and the density-of-states distribution for p-Si before and after high-pressure $\mathrm{H}_{2} \mathrm{O}$ vapor treatment. The pristine p-Si included many defects at grain boundaries, and these were passivated by oxygen, forming Si-O-Si during the high-pressure $\mathrm{H}_{2} \mathrm{O}$ vapor treatment. Hall measurements also revealed that the $\mu$ value for the p-Si increased markedly with decreasing $N_{\mathrm{a}}$ after the treatment. Therefore, the density of tail states near the valence and conduction bands suppressed to be lower with decreasing the defect density at mid gap by the treatment. As a result, Fermi level shifted toward mid gap, resulting in an increase in $\mathrm{V}_{\mathrm{b}}$. Furthermore, CMD with a negatively charged mist precursor promoted the adhesion of PEDOT:PSS to the p-Si. In fact, higher $\mathrm{V}_{\text {oc }}$ and $J_{\text {sc }}$ values were obtained compared with those of SC, although further improvement of FF values is required. The highest occupied molecular orbital (HOMO) of the organic -valence band maximum $\left(E_{\mathrm{v}}\right)$ of the c-Si offset was negligibly small, implying that the photogenerated holes can pass from p-Si to PEDOT:PSS with no resistive loss. In addition, the CMD PEDOT:PSS film with a mesh bias $V_{m}$ used to charge the mist precursor exhibited more prominent uniaxial optical anisotropy. Thus, the SE study revealed that the extraordinary refractive index and hole mobility of PEDOT:PSS increased with increasing $\mathrm{V}_{\mathrm{m}}$, resulting in improved photovoltaic performance [5, 11, 24]. Improved adhesion of PEDOT:PSS to p-Si and the hole mobility of PEDOT:PSS using CMD with a charged mist precursor results in the efficient suppression of defect generation at the organic/p-Si interface, leading to increased photovoltaic performance.

\section{Conclusions}


In summary, we investigated the photovoltaic performance of PEDOT:PSS/n-type p-Si heterojunction solar cell devices. High-pressure $\mathrm{H}_{2} \mathrm{O}$ vapor treatment of p-Si efficiently passivated dangling bond defects at the grain boundaries. Chemical mist deposition of conductive PEDOT:PSS using a negatively charged mist precursor significantly improved the adhesion of PEDOT:PSS to p-Si, resulting in enhanced carrier collection efficiency in the 850$1000 \mathrm{~nm}$ region. As a consequence, efficient PEDOT:PSS/p-Si heterojunction solar cell were obtained with the highest $\eta$ of $9.7 \%$, a $J_{\text {sc }}$ of $33.5 \mathrm{~mA} / \mathrm{cm}^{2}$, a $V_{\text {oc }}$ of $0.54 \mathrm{~V}$, and a $F F$ of 0.53 . Such organic/p-Si heterojunction cells can potentially further deliver a high $F F$ and a high conversion efficiency along with sufficient passivation of dangling bonds and the organic adhesion on the pSi.

\section{Acknowledgments}

This research was supported in part by a Japan Science and Technology (JST) Agency (A-step) grant and a Leading-edge Industry Design Project of Saitama prefecture. The authors thank Drs. S. Wakamatsu and M. Azuma of Tokuyama Co., Ltd. for supplying n-type poly-Si wafers.

\section{References}

[1] S. Avasthi, S. Lee, Y. -L. Loo, and J. C. Sturm, Adv. Mater. 23 (2011), 5672.

[2] T. Song, S. T. Lee, B. Sun, Nano Energy 1 (2012) 654-673

[3] L. He, D. Lai, H. Wang, C. Jiang, and Rusli, Small 8 (2012), 1664.

[4] Q. Liu, I. Khatri, R. Ishikawa, K. Ueno, and H. Shirai, Appl. Phys. Lett. 102 (2013), 183503.

[5] Q. Liu, T. Imamura, T. Hiate, I. Khatri, Z. Tang, R. Ishikawa, K. Ueno, and H. Shirai, Appl. Phys. Lett. 102 (2013), 243902.

[6] Y. Zhu, T. Song, F. Zhang, S. -T. Lee, and B. Sun, Appl. Phys. Lett. 102 (2013), 113504.

[7] J. Schmidt, V. Titova, and D. Zielke, Appl. Phys. Lett. 103 (2013), 83901.

[8] A. S. M. Pietsch, M. Bashouti, and S. Christiansen, J. Phys. Chm. C 118 (2013), 9049.

[9] M. Y. Bashouti, M. Pietsch, G. Brönstrup, V. Sivakov, J. Ristein, S. Christiansen, Prog. Photovoltaics 22 (2013), 1050.

[10] M. Pietsch, S. Jäcke, and S. Christiansen, Appl. Phys. A 115 (2014), 1109. 
[11] M. Ono, Z. Tang, R. Ishikawa, T. Gotou, Z. Tang, K. Ueno, and H. Shirai, Appl. Phys. Express 50 (2012), 032301.

[12] I. Khatri, Z. Tang, Q. Liu, R. Ishikawa, K. Ueno, and H. Shirai, Appl. Phys. Lett. 102 (2013), 063508.

[13] Y. Zhang, F. Zu, S-T. Lee, L. Liao, N. Zhao, and B. Sun, Adv. Energy. Mater. 4 (2014), 201300923.

[14] I. Khatri, Z. Tang, T. Hiate, Q. Liu, R. Ishikawa, K. Ueno, and H. Shirai, Thin Solid Films 558C (2014), 306.

[15] Q. Liu, I. Khatri, R. Ishikawa, A. Fujimori, K. Ueno, K. Manabe, H. Nishino, and H.Shirai, Appl. Phys. Lett. 103 (2013), 163503.

[16] Q. Liu, M. Ono, Z. Tang, R. Ishikawa, K. Ueno, and H. Shirai, Appl. Phys. Lett. 100 (2013), 183901.

[17] Y. Dan, K. Seo, K. Takei, J. H. Meza, A. Javey, and K. B. Crozier, Nano Lett. 11 (2011), 2527.

[18] T.-G Chen, B.-Y Huang, E.-C Chen, P. Yu, and H.-F Meng, Appl. Phys. Lett. 101 (2012), 033301.

[19] I. Khatri, T. Imamura, A. Uehara, R. Ishikawa, K. Ueno, and H. Shirai, Phys. Sta. Sol. C 9 (2012), 2134.

[20] T. Sameshima, M. Satoh, K. Sakamoto, K. Ozaki, and K. Saitou, Jpn. J. Appl. Phys. 37 (1998), 4254.

[21] T. Sameshima, K. Sakamoto, and K. Asada, Appl. Phys. A 69 (1999), 221.

[22] Y. Ding, R. Gresback, Q. Liu, S. Zhou, X. Pi and T. Nozaki, Nano Energy 9 (2014), 25.

[23] H. Fujiwara and M. Kondo, J. Appl. Phys. 101 (2007), 054516.

[24] T. Hiate, N. Miyauchi, Q. Liu, R. Ishikawa, K. Ueno, and H. Shirai, J. Appl. Phys. 115 (2014), 123514.

[25 T. Unold, M. Rösch, and G. H. Bauer, J. Non-Cryst. Solids 1033 (2000), 266.

[26] A. Farah, S. Rutledge, A. Schaarschmidt, R. Lai, J. Freedman, and A. Helmy, J. Appl. Phys. 112 (2012), 113709. 
Graphical abstract:

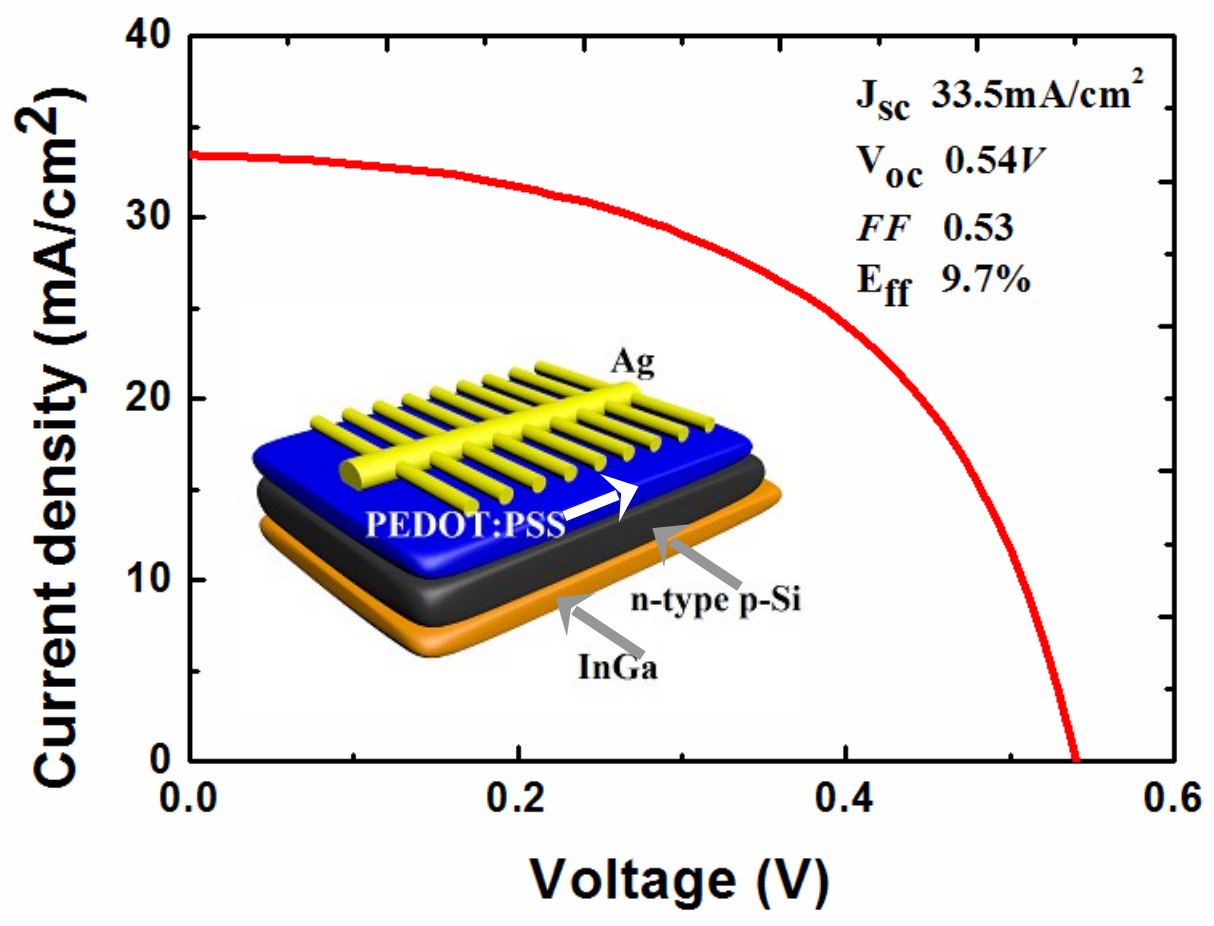

